\title{
COMPUTER-ASSISTED INSTRUCTION ON STUDENTS' ACADEMIC ACHIEVEMENT AND ENGAGEMENT IN SCIENCE
}

\author{
Evangeline Rafael Dap-og ${ }^{1 *}$ and Maris Jade Q. Orongan ${ }^{2}$ \\ ${ }^{1}$ Banlag Integrated School, Philippines \\ ${ }^{2}$ Central Mindanao University, Philippines
}

\begin{abstract}
This study determined the students' academic achievement and engagement in science. A quasi-experimental research design was utilized. The study results showed that students exposed to CAI obtained "fairly satisfactory" results in the post-test, while those exposed to non-CAI showed "needs improvements" both in the pretest and post-test. Moreover, for students' engagement in science, the CAI group had a high engagement level for affective, cognitive, and behavioral domains. In contrast, the non-CAI group had moderate engagement before and after the intervention. The students' academic performance in science exposed to CAI is significantly higher than those exposed to nonCAI. Also, there is a significant difference in students' engagement level for a cognitive domain in favor of CAI. It is concluded that CAI as a science learning tool enhances the students' cognitive engagement.
\end{abstract}

Keywords: computer-assisted instruction, academic achievement, engagement, science

Teaching science requires a lot of visualizations and experiments. Thus, every school should have science laboratories where students can experiment and explore to enhance their understanding of optimal learning concepts and interests. However, not all schools in the country have enough laboratory equipment, especially in public schools (Estipular \& Roleda, 2018). This problem is one of the issues raised to be the primary cause of failure among science students. The 2018 Programme for International Student Assessment (PISA) revealed Filipino students' low performance in science, where the Philippines garnered a rank of 78 out of 79 participating countries.

Teaching physics in high school is in no way simple and easy. The usual students' perception of understanding and learning physics is difficult (Oon \& Subramaniam, 2011). Passivity and lack of engagement, resulting in low academic achievement, are the principal problems in education that must be addressed (Cutler, 2007). Several factors have been identified to be responsible for these poor performances and lack of interest from various studies conducted (Gunuc, 2014), and one influential factor in student engagement (Schleicher, 2018). Academic achievement has consistently been regarded as an essential outcome of student engagement (Barghaus et al., 2017; Lei et al., 2018).

To address the poor achievement and engagement in science, the Department of Education (DepEd) Philippines pursued the integration of Information and Communications Technology (ICT) in the school curriculum. Under this framework, the objective is to develop teacher competence in using ICT, especially in the design, production, and use of ICT-based instructional materials (Itaas, as cited in Cupida, 2014, p. 2). This ICT has been integrated into a variety of ways in the teaching-learning process, such as Computer Assisted Instruction (CAI), to facilitate students' learning. 
Physics Education Technology (PhET) and other computer applications have been used as CAI tools in providing activities to represent abstract ideas, especially in physics. There is considerable evidence that PhET interactive simulations can be powerful tools for achieving science students' learning (Apostol, 2016). Many studies have provided evidence on CAI's effectiveness or PhET integration in physics instruction in improving students' academic achievement (Apostol, 2016; Halil \& Sensoy, 2018).

Hence, this study was conducted to examine CAI's effectiveness in enhancing students' academic achievement and science engagement. This study's findings would serve as a basis for curriculum makers, school administrators, and teachers for curriculum revision and enhancement to meet $21 \mathrm{st}$ century science education's global challenges.

\section{Objectives of the Study}

This study examined Computer Assisted Instruction's effectiveness on students' academic achievement and engagement in Grade 9 science students. Specifically, it aimed to: (a) determine the academic achievement of students who are exposed to CAI and those exposed to non-CAI; (b) describe the level of engagement of students who are exposed to CAI and those exposed to non-CAI in terms of cognitive, affective, and behavioral dimensions; (c) ascertain the significant difference in students' academic achievement exposed to CAI and those exposed to non-CAI; and (d) find out the significant difference in students' engagement to CAI and those exposed to non-CAI in terms of cognitive, affective, and behavioral dimensions.

\section{Conceptual Framework}

Figure 1 presents the relationship between the independent and dependent variables employed in the study.

\section{Method}

The study employed a quasi-experimental design. The respondents were two heterogenous sections. A total of 55 students in Grade 9 were chosen as research respondents. There were 28 participants in the CAI group and 27 in the non-CAI group.

\section{Research Instruments}

Assessments were employed during the collection of data. This was to determine the academic achievement and engagement in terms of affective, behavioral, and cognitive dimensions. After the content validation, the instruments were pretested and piloted to Grade 10, 11, and 12 students for reliability to ensure internal consistency using Cronbach's alpha. The instruments' content validity and reliability (0.820) were conducted carefully for temporal, spatial, and ethical considerations. A total number of 55 items constituted the pretest and posttest. The Students' Engagement in School Questionnaire (SESQ) was used to determine students' engagement. The questionnaire was adapted from Hart et al. (2011) and consisted of three domains: affective, behavioral, and cognitive engagement. The reliability coefficients for each domain were: affective engagement $=0.88$, 
Independent Variables

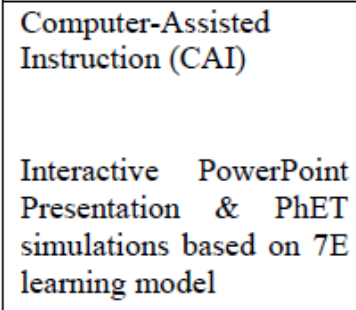

Dependent Variable

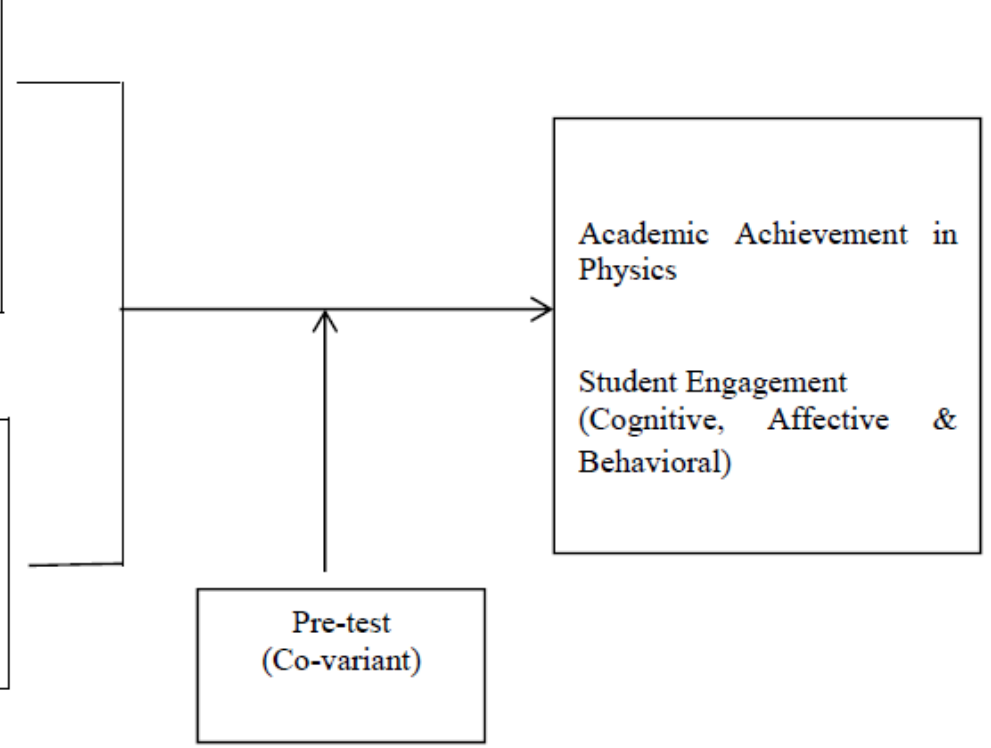

Figure 1. Schematic diagram showing the relationship between the independent and dependent variables.

behavioral engagement $=0.85$, and cognitive engagement $=0.93$. The affective domain consists of 9 items, behavioral consists of 11 , and the cognitive domain consists of 12 items.

\section{PowerPoint Presentations}

PowerPoint Presentation is part of the Information and Communications Technology (ICT) developed by Microsoft and consists of slides allowing the user to present messages. PowerPoints are used in the classroom to support student learning by combining colorful images, animations, videos, graphs, and different media to illustrate a lesson, making it interactive, bringing learning experiences to the next level. In this study, various PowerPoint application tools were utilized, such as hyperlinks, animations, picture puzzles, and self-scoring games, to provide an interactive and engaging presentation. The topics included: Horizontal Motion, Vertical Motion, Impulse and Momentum, Conservation of Momentum, Work, Power, Kinetic Energy, and Potential Energy that were content validated.

\section{PhET Simulations}

PhET simulations are a suite of research-based interactive computer simulations for teaching and learning physics and other sciences. This was run online or downloaded ahead for free from its website. The simulations are an animated, interactive, and game-like environment where students learn through exploration. In this study, PhET simulations were used to help introduce topics, build concepts or skills during the lecture, reinforce ideas in class laboratory activities, and provide final 
reviews and homework reflections. The topics were content validated that includes Motion in two dimensions and Conservation of Mechanical Energy.

\section{Implementation of Computer Assisted Instruction}

The 7E learning cycle model was adopted in employing the CAI. These were given to the learning materials of the students. The students (individually or by the group) followed the subsequent phases during the CAI implementation.

\section{Implementation of non-Computer Assisted Instruction}

In the non-CAI, the conventional teaching approach was utilized to teach desired concepts reflected in the table of specifications of the research instrument for measuring students' academic achievement. The regular use of teacher-manipulated PowerPoint presentations in LED TV, drills, and practices found in the DepEd learner's material is implemented. The non-CAI group topics were briefly taught using the same strategies as the CAI group but without using computers. Students answered the same activity sheets provided in the module, and their outputs are rated according to the rubrics used in determining their proficiency level. To eliminate the teacher factor effect, the researcher herself was the one to handle and teach the students in both groups.

\section{Statistical Treatment}

Descriptive statistics such as means, percentages, and standard deviation were employed to ascertain students' academic achievement and engagement with CAI and those exposed to non-CAI.

An analysis of covariance (ANCOVA) was used to determine the significant difference in the students' academic achievement exposed to CAI and exposed non-CAI, using pretest scores as the covariate. The $t$-test was used to ascertain the significant difference between students' engagement exposed to CAI and those exposed to non-CAI.

\section{Results and Discussion}

Table 1 presents the academic achievement of science students exposed to CAI and those exposed to non-CAI in terms of pretest and posttest. Data show that the overall pretest means percentage score (MPS) of the CAI group and the non-CAI are $32.47 \%$ and $29.90 \%$. This indicates that both groups need improvement. The results imply that the students under CAI and non-CAI have weak prior knowledge about physics concepts.

\section{Level of Students' Academic Achievement in Science}

As reflected in Table 1, the overall posttest MPS under CAI is $63.25 \%$, indicating a fairly satisfactory result. Out of 28 students, there were three groups of five (17.8\%) students who achieved very satisfactory, satisfactory, and fairly satisfactory results. Twelve (42.9\%) got below 59\%, described as needs improvement. This implies that the students need more basic foundations of their learning competencies and skills in science, particularly physics. 
Table 1

Students' academic achievement in science

\begin{tabular}{|c|c|c|c|c|c|c|c|c|c|}
\hline \multicolumn{5}{|c|}{ CAI } & & \multicolumn{4}{|c|}{ Non-CAI } \\
\hline \multirow[t]{2}{*}{ Grade Scale } & \multicolumn{2}{|c|}{ Pretest } & \multicolumn{2}{|c|}{ Posttest } & & \multicolumn{2}{|c|}{ Pretest } & \multicolumn{2}{|c|}{ Posttest } \\
\hline & $\mathrm{N}$ & $\%$ & $\mathrm{~N}$ & $\%$ & & $\mathrm{~N}$ & $\%$ & $\mathrm{~N}$ & $\%$ \\
\hline $90-100$ & 0 & 0 & 1 & 3.6 & & 0 & 0 & 0 & 0 \\
\hline $80-89$ & 0 & 0 & 5 & 17.8 & & 0 & 0 & 0 & 0 \\
\hline $70-79$ & 0 & 0 & 5 & 17.8 & & 0 & 0 & 3 & 11.1 \\
\hline $60-69$ & 1 & 3.6 & 5 & 17.8 & & 0 & 0 & 11 & 40.7 \\
\hline 59 below & 27 & 96.4 & 12 & 42.9 & & 27 & 100 & 13 & 48.1 \\
\hline Total & 28 & 100 & 28 & 100 & & 27 & 100 & 27 & $100 \%$ \\
\hline $\begin{array}{l}\text { Overall } \\
\text { mean/ } \\
\text { MPS }\end{array}$ & \multicolumn{2}{|c|}{$\begin{array}{c}=17.8 \quad \bar{x} \\
\text { MPS }=32.47 \\
\quad(\mathrm{NI})\end{array}$} & \multicolumn{2}{|c|}{$\begin{array}{l}34.8 \\
\text { MPS=63.25 } \\
\text { (Fair) }\end{array}$} & $=$ & \multicolumn{2}{|c|}{\begin{tabular}{l}
\multicolumn{1}{c}{$\bar{x}$} \\
$=16.4$ \\
MPS= 29.90 \\
$\quad(\mathrm{NI})$
\end{tabular}} & \multicolumn{2}{|r|}{$\bar{x}$} \\
\hline
\end{tabular}

Legend: $90-100=$ Outstanding; 80-89 = Very satisfactory; 70-79 = Satisfactory; 60-69 = Fairly satisfactory; 59below $=$ Needs improvement

The study's findings were strengthened from the studies conducted by Cupida (2014), Vegafria (2016), and Tyagi (2014) that the physics performance of students can be enhanced through Computer-Based Instruction and Multimedia Learning. It was also stressed by Apostol (2016) that knowledge in physics could be achieved significantly better using the PhET simulation method than the lecture method.

Further, Batuyong and Antonio (2018) explained that PhET simulation is an interactive, engaging activity that motivates students to try more, work more, and learn more about the assigned activity and that technology integration in the classroom has a potential value in supporting students' learning through the experiences with their environment, the connection of new knowledge to prior knowledge, and interaction with others.

On the other hand, posttest MPS of students who were exposed to non-CAI were broken down as follows: three (11.1\%) students garnered a satisfactory result, $11(40.7 \%)$ of them got a fairly satisfactory, and $48.1 \%$ need improvement. The overall MPS of the non-CAI group is $55.82 \%$, which means it needs improvement. This shows that the students have not mastered the learning competencies in the lesson taught.

This study's results conform to the consolidated MPS in NAT 2018, which is below the proficiency level. It conforms to the current findings of the study. The meager results of students' academic achievement may be attributed to weak reading comprehension skills, lack of motivation from most teachers, inadequate infrastructural facilities, faulty textual materials, students' attitude to learning, lack and of inappropriate teaching method (Chinwendu \& Patience, 2017). 
Table 2

Summary of students' engagement level towards science

\begin{tabular}{lllllllll}
\hline Domain & \multicolumn{1}{c}{ CAI } & \multicolumn{7}{c}{ Non-CAI } \\
\cline { 2 - 8 } & Pretest & QI & Posttest & QI & Pretest & QI & Posttest & QI \\
Cognitive & 3.58 & High & 3.85 & High & 3.32 & Moderate & 3.38 & Moderate \\
Affective & 4.04 & High & 4.08 & High & 3.49 & Moderate & 3.74 & High \\
Behavioral & 3.31 & Moderate & 3.69 & High & 2.91 & Moderate & 3.39 & Moderate \\
\hline Overall & 3.61 & High & 3.86 & High & 3.22 & Moderate & 3.48 & Moderate \\
Mean & & & & & & & & \\
\hline
\end{tabular}

Legend: 4.51-5.0 = Very high; 3.51-4.5 = High; 2.51-3.5 = Moderate; 1.21-2.5 = Low; 1.00-1.20 = Very low

\section{Level of Students' Engagement in Science}

Moreover, this finding corroborates the study of Estipular and Roleda (2018). They reported that the lack of laboratory rooms and equipment hinders the students' experiences to connect theories with discipline.

As shown in Table 2, the engagement level of the CAI group before the intervention is 3.61, which is high with the following domains in their order of preferences, namely: affective (4.04), cognitive (3.58), and behavioral (3.31). In comparison, the non-CAI group was moderate with a level of 3.22 with the following domains in their order of preferences: affective (3.49), cognitive (3.32), and behavioral (2.91). After the intervention, the engagement of the CAI group increased with a mean score of 3.86, which is still high engagement with the following domain in their order of preferences: affective (4.08), cognitive (3.85), and behavioral (3.69). In contrast, the non-CAI group is still moderate engagement with a mean score of 3.48 with the following domains in their order of preferences: affective (3.74), behavioral (3.39), and cognitive (3.38).

The result revealed that all CAI and non-CAI improved all engagement domains because the teacher's instruction delivery improves students' engagement level (Arjomandi et al., 2008). Additionally, the interactions, hands-on activities, and science applications contribute to a higher mean level of student engagement (Bennett \& Thompson, 2011).

The findings of Cupida (2014) support the idea that the integration of multimedia learning as an instructional approach effectively enhances student engagement and develops a positive attitude toward learning physics. Vegafria's (2016) study reported that students' attitudes when exposed to multimedia learning are positive. In comparison, students exposed to non-multimedia are moderately positive. Mahmood (2006) supports that the CAI group outperformed the non-CAI group in science's cognitive domain.

Furthermore, this study revealed that affective engagement is the highest level of engagement among the three engagement domains. According to Reschly and Christenson (2012), having positive attitudes toward school and school-related activities is an essential driver of students' engagement in learning activities exhibiting more academic achievement. Higher levels of affective engagement with 
Table 3

Percentage distribution of respondents according to gender

\begin{tabular}{llll}
\hline Gender & Frequency & Percent & Valid Percent \\
\hline Male & 27 & 49.1 & 49.1 \\
Female & 28 & 50.9 & 50.9 \\
Total & 55 & 100.0 & 100.0 \\
\hline
\end{tabular}

science were found in classrooms where students reported that various interaction measures, hands-on activities, and applications in science took place frequently. Thus, students' high affective engagement may be correlated to Bloom's (1956) engagement that CAI has improved their interest, enjoyment, and sense of belonging. Next to affective engagement is cognitive engagement. CAI strategies meet students' needs and expectations that provide multi-tasking and interactive learning and presenting information through various media (Jukes, 2005). Cognitive engagement has been improved by participating in deep cognitive processing and better understanding and retaining meaningful material. The lowest engagement level is behavioral engagement, which could be attributed to teacher interactions among students around academic tasks (Becker et al., 2018). The limitation of this CAI might be the interaction of teachers among students.

Therefore, the teacher must be responsible for making sure that the environment is right and encourages learning using various teaching methods, a variety of learner-centered teaching, and learning approaches, including assessment and classroom management. More specifically, teachers need to identify various factors that affect student learning, including how learners learn, alternative conceptions that many learners hold, safety issues, availability of appropriate resources, and the values held by various stakeholders in the education process.

Table 3 provides the distribution of respondents according to gender. It shows that $49.1 \%$ of the respondents are male while the remaining $50.9 \%$ are female.

The $t$-test statistics of the students' academic achievement and engagement in science based on gender are presented in Table 4. The table shows that there is no significant difference between students' academic achievement and engagement in science based on gender. As presented in the table, students' academic achievement has no significant difference between male and female, with a $t$-value of .385 and a probability value of $.702(p>0.05)$. The overall engagement level has no significant difference between male and female, with a $t$-value of .622 and a probability value of $.537(p>0.05)$. Moreover, the three domains: cognitive $(t=0.385, p=.702)$, affective $(t=0.054, p=.957)$, and behavioral $(t=0.340, p=.735)$ show no significant difference between male and female.

\section{Analysis of Covariance (ANCOVA) of Academic Achievement between Treatments}

Presented in Table 5 is the analysis of covariance (ANCOVA) of posttest results between treatments, using pretest scores as the covariate. As shown in the table, the CAI group with a mean score of 63.24 performed better than the non-CAI group with a mean score of 55.85, $F(2,52)=47.63, p<.001$, indicating high significance. 
Table 4

Results of t-tests on students' academic achievement and engagement in science based on gender

\begin{tabular}{llllcc}
\hline Domain & Gender & Mean & SD & $t$-value & Sig. \\
\hline Academic & Male & 43.8148 & 6.08932 & .385 & .702 \\
Achievement & Female & 43.1071 & 7.45028 & & .702 \\
Cognitive & Male & 43.8148 & 6.08932 & .385 & .957 \\
& Female & 43.1071 & 7.45028 & & .054 \\
Affective & Male & 35.3333 & 6.17065 & & .735 \\
& Female & 35.2500 & 5.17562 & .340 & .537 \\
Behavioral & Male & 42.8148 & 6.82775 & & .622 \\
\end{tabular}

*Significant at 0.05 level

The study findings corroborate the results of several studies conducted by Abdullahi et al. (2018), Apostol (2016), Cupida (2014), Julius et al. (2018), and Serin (2011). They found that students exposed to CAI performed significantly better than those exposed to the conventional instruction method. Exposure of students to different CAI materials, such as PhET simulation and PowerPoint presentations, will enhance students' interest and knowledge to positively affect students as they feel more competent and skilled during the learning process (Chinwendu \& Patience, 2017). According to Tyagi (2014), immediate feedback on students' performance in the CAI instruction will motivate them. In effect, this will produce better student learning outcomes in physics.

Table 6 exhibits the $t$-test results toward students' engagement in science between CAI and non-CAI groups. As presented in the table, the overall engagement level is significantly different between the CAI and non-CAI group, with a $t$-value of -3.056 and a probability value of $.003(p<0.05)$. Moreover, the three domains: cognitive $(t=-3.311, p=0.002)$, affective $(t=-2.126, p=.038)$, and behavioral $(t=-2.134, p=0.38)$ show significant difference between the CAI and non-CAI group.

Table 5

Analysis of Covariance (ANCOVA) of posttest results between treatments

\begin{tabular}{|c|c|c|c|c|c|c|}
\hline Group & \multicolumn{2}{|c|}{ Mean } & SD & \multicolumn{3}{|c|}{$\mathrm{N}$} \\
\hline CAI & \multicolumn{2}{|c|}{63.24} & 12.56 & \multicolumn{3}{|c|}{28} \\
\hline Non-CAI & \multicolumn{2}{|c|}{55.85} & 14.77 & \multicolumn{3}{|c|}{27} \\
\hline Total & \multicolumn{2}{|c|}{59.60} & 14.11 & \multicolumn{3}{|c|}{55} \\
\hline Source & SS & $\mathrm{df}$ & MS & $F$-value & & Sig. \\
\hline Group & 18225.528 & 2 & 9112.764 & 47.826 & & $<.001 *$ \\
\hline Pretest & 89.703 & 1 & 89.703 & .471 & & .496 \\
\hline Error & 9908.129 & 52 & 190.541 & & & \\
\hline Total & 206145.455 & 55 & & & & \\
\hline
\end{tabular}

*Significant at 0.05 level 
Table 6

Results of t-tests on students' engagement in science between treatments

\begin{tabular}{|c|c|c|c|c|c|}
\hline Domain & Group & Mean & SD & $t$-value & Sig. \\
\hline \multirow[t]{2}{*}{ Cognitive } & CAI & 3.85 & .51 & -3.311 & $.002 *$ \\
\hline & Non-CAI & 3.38 & .53 & & \\
\hline \multirow[t]{2}{*}{ Affective } & CAI & 4.09 & .59 & -2.126 & .038 \\
\hline & Non-CAI & 3.74 & .62 & & \\
\hline \multirow[t]{2}{*}{ Behavioral } & CAI & 3.69 & .56 & -2.134 & .038 \\
\hline & Non-CAI & 3.39 & .48 & & \\
\hline \multirow[t]{2}{*}{ ENGAGEMENT } & CAI & 3.85 & .46 & -3.056 & $.003 *$ \\
\hline & Non-CAI & 3.48 & .44 & & \\
\hline
\end{tabular}

*Significant at 0.05 level

The result of this study is in line with Effiong and Ekpo (2018). Their research shows that students exposed to CAI enhance teaching and learning through dynamic interaction and engaging content. It also allows students to apply existing knowledge and produce new experiences. This research also supports Bada (2015), wherein they found out that CAI is engaging and promotes a constructivist classroom where students can actively explore and learn.

Bennett and Thompson's (2011) findings support that students' engagement is at higher levels in which interaction, hands-on activities, and science applications occurred in the teaching-learning process. This study's results are in line with Cupida (2014) and Vegafria (2016) that the integration of multimedia learning as an instructional approach is effective in enhancing student engagement and developing a positive attitude towards learning physics. Cupida (2014) supports that Computer-Based Instruction has improved student engagement, especially on the cognitive level, which had been affected by their exploration of technology applications, and the CAI group outperformed the nonCAI group in the cognitive domain (Mahmood, 2006). On the other hand, this study's result contradicts the result of Xingeng and Jianxiang (2012) in that teachers' use of PowerPoint makes the students easy to feel tired and cannot concentrate. Students have a more positive attitude towards the lecture method than PowerPoint, which implies more engagement.

The result further implies that only cognitive engagement showed a significant difference between the groups out of the three student engagement domains. Student engagement on learning tasks is crucial; various factors need to be considered to do so. Teachers' instructional activities such as interactive learning, presenting information through various media, and ICT develop engaging knowledge. CAI activities may cognitively engage students because they are self-directed, simulating, and hands-on, stimulating their curiosity.

In general, the evidence suggests that the use of ICT enables more productive and more engaging learning. Teachers may use a wide variety of strategies to promote positive emotions in students, facilitating the learning process, minimizing negative behaviors, or preventing students from dropping out and making sure that there is a child-friendly, gender-sensitive, safe, and motivating environment.

\section{Conclusions}

Based on the findings of the study, the following conclusions were drawn: 
- The academic achievement in science of the Grade 9 students in pre-test for the CAI and nonCAI had shown "needs improvement" results. After the intervention, both groups improved that the CAI group showed a "fairly satisfactory" result, while the non-CAI group still "needs improvement."

- The engagement of the CAI group towards science before and after the intervention was high. At the same time, the engagement of the non-CAI group before and after the intervention was moderate. The students' engagement with computer-assisted instruction favored the three domains: cognitive, affective, and behavioral. Of these domains, affective engagement obtained a high mean value, and the least is the behavioral domain.

- Moreover, those exposed to CAI have a significantly higher post-test compared to those exposed to non-CAI.

- Those exposed to CAI have a higher significant difference in the engagement level for affective, cognitive, and behavioral domains than those exposed to non-CAI.

\section{Recommendations}

The results and findings of the study have led to the following recommendations for further research and actions:

- The integration of CAI as a promising approach in science teaching would promote positive cognitive, affective, and behavioral learning outcomes; students may be exposed to wellplanned CAI to develop active learning experiences further.

- Science educators may use innovative CAI strategies such as PhET interactive simulationbased activities, interactive PowerPoint, and the like to improve the students' conceptual understanding in learning physics through visualization and to augment academic achievement.

- Science educators may also employ CAI as innovative teaching in increasing students' engagement toward science and assessment tools to support instructional materials to cater to students' current needs, skills, and abilities for active and meaningful science learning.

- School administrators may allocate appropriate funds for ICT facilities, tools, and software that can be used to facilitate the teaching and learning process. They may conduct comprehensive seminars, training, and workshops related to ICT to the teachers to enhance their ICT competency level to become more competent and effective in using technology in the classroom for the betterment of outcomes in physics.

Finally, future researchers may consider other variables of examining and measuring student engagement in school that would directly relate to their needs and interests and promote positive learning outcomes. 


\section{References}

Abdullahi, B., Yusuf, L. A., \& Mohammed, I. A. (2018). A study of the effects of computer-assisted packages on senior secondary students' performance in chemistry in Zaria educational zone, Kaduna State Nigeria. International Journal of Secondary Education, 6(4), 59-65. http://article.ijsedu.org/pdf/10.11648.j.ijsedu.20180604.12.pdf

Apostol, C. L. G. (2016). Physics education technology (PhET) simulation-aided instruction: Its effectiveness in enhancing grade 10 students' proficiency level in physics [Unpublished master's thesis]. Mindanao State University.

Arjomandi, A., Seufert, J., O’Brien, M., \& Anwar, S. (2018). Active teaching strategies and student engagement: A comparison of traditional and non-traditional business students. e-Journal of Business Education and Scholarship of Teaching, 12(2), 120-140. https://files.eric.ed.gov/fulltext/EJ1193332.pdf

Bada, S. O. (2015). Constructivism learning theory: A paradigm for teaching and learning. IOSR Journal of Research \& Method in Education, 5(6), 66-70.

Barghaus, K., Fantuzzo, J., LeBoeuf, W., Henderson, C., Li, F., \& McDermott, P. (2017). Problems in classroom engagement: Validation of an assessment for district-wide use in the early primary grades, Early Education and Development, 28(2), 154-166. https://doi.org/10.1080/10409289.2016.1197012

Batuyong, C. T., \& Antonio, V. V. (2018). Exploring the effect of PhET® interactive simulationbased activities on students' performance and learning experiences in electromagnetism. Asia Pacific Journal of Multidisciplinary Research, 6(12), 121-131. http://www.apjmr.com/wpcontent/uploads/2018/02/APJMR-2017.6.2.15.pdf

Becker, C., Cooper, N., Atkins, K., \& Martin, S. (2009). What helps students thrive? An investigation of student engagement and performance. Recreational Sports Journal, 33(2), 139-149. https://doi.org/10.1123/rsj.33.2.139

Bennett, J., \& Thompson, G. (2011) Science teaching and learning activities and students' engagement in science. International Journal of Science Education, 35(8), 1325-1343. https://doi.org/10.1080?09500693.2011.608093

Bloom, B. S. (1956). Taxonomy of educational objectives, handbook 1: The cognitive domain. David McKay.

Chinwendu, N. S., \& Patience, C. (2017). Computer-assisted instruction (CAI) on students' interest and achievement in physics in Imo state, Nigeria. IOSR Journal of Research \& Method in Education, 7(3), 53-58. https://doi.org/10.9790/7388-0703045358

Cupida, S. M. (2014). Effects of computer-based instruction on the academic achievement of students in physics through the guided-inquiry approach [Unpublished master's thesis]. Central Mindanao University.

Cutler, A. (2007). Creeping passivity. Journal of College Science Teaching, 36(6), 6-7.

Effiong, A., \& Ekpo, O. (2018). Interactive effect of PowerPoint instructional package and academic performance of educational technology students in the University of Calabar. SSRN Electronic Journal, 1(2), 1-12. https://doi.org/10.2139/ssrn.2853412

Estipular, M. K. L., \& Roleda, L. S. (2018, June 20-22). The use of interactive lecture demonstration with interactive simulation in enhancing students' conceptual understanding in physics [Paper presentation]. DLSU Research Congress 2018, Manila, Philippines. https://www.dlsu.edu.ph/wp-content/uploads/pdf/conferences/research-congressproceedings/2018/lli-18.pdf

Gunuc, S. (2014). The relationships between student engagement and their academic achievement. International Journal on New Trends in Education and Their Implications, 5(4), 199-214. http://www.ijonte.org/FileUpload/ks63207/File/19.gunuc.pdf 
Halil, Y., \& Sensoy, O. (2018). The effect of science teaching enriched with technological applications on the science achievements of 7th grade students. Journal of Education and Training Studies, 6(9), 53-68. https://doi.org/10.11114/jets.v6i9.3363

Hart, S. R., Stewart, K., \& Jimerson, S. R. (2011). The Student Engagement in Schools Questionnaire (SESQ) and the Teacher Engagement Report Form-New (TERF-N): Examining the preliminary evidence. Contemporary School Psychology, 15, 67-79. https://files.eric.ed.gov/fulltext/EJ934707.pdf

Jukes, I. (2005). Understanding digital kids (DKs): Teaching \& learning in the new digital landscape.

Julius, J. K., Twoli, N. W., \& Maundu, J. N. (2018). Effect of computer aided instruction on students' academic and gender achievement in chemistry among selected secondary school students in Kenya. Journal of Education and Practice, 9(14), 56-63. https://www.iiste.org/Journals/index.php/JEP/article/view/42386/43652

Lei, H., Cui, Y., \& Zhou, W. (2018). Relationships between student engagement and academic achievement: A meta-analysis. Social Behavior and Personality: An International Journal, 46(3), 517-528. https://doi.org/10.2224/sbp.7054

Mahmood, S. J. (2006). Examining the mathematics performance of developmental mathematics students when computer-assisted instruction is combined with traditional strategies [Unpublished doctoral dissertation]. Texas Southern University. https://www.learntechlib.org/p/12249/

Oon, P.-T., \& Subramaniam, R. (2011). On the declining interest in physics among students-From the perspective of teachers. International Journal of Science Education, 33(5),727-746. https://doi.org/10.1080/09500693.2010.500338

Organisation for Economic Cooperation and Development. (2019). PISA 2018 results (Volume I): What students know and can do. https://doi.org/10.1787/5f07c754-en

Reschly, A. L., \& Christenson, S. L. (2012). Jingle, jangle, and conceptual haziness: Evolution and future directions of the engagement construct. In S. L. Christenson, A. L. Reschly, \& C. Wylie (Eds.), Handbook of research on student engagement (pp. 3-19). Springer. https://doi.org/10.1007/978-1-4614-2018-7_1

Schleicher, A. (2018). Educating learners for their future, not our past. ECNU Review of Education, 1(1), 58-75. https://doi.org/10.30926/ecnuroe2018010104

Serin, O. (2011). The effects of the computer-based instruction on the achievement and problemsolving skills of the science and technology students. Turkish Online Journal of Educational Technology, 10(1), 183-201. http://www.tojet.net/articles/v10i1/10119.pdf

Tyagi, S. (2014). Comparative effectiveness of computer-assisted instruction (CAI) with traditional instruction at the teacher training level. International Journal of Research, 1(9), 71-77. https://journals.pen2print.org/index.php/ijr/article/view/611

Vegafria, L. A. (2016). Multimedia learning: An integrated teaching delivery model on students' achievements and attitudes in grade 10 science [Unpublished master's thesis]. Central Mindanao University.

Xingeng, D., \& Jianxiang, L. (2012). Advantages and disadvantages of PowerPoint in lectures to science students. International Journal of Education and Management Engineering, 2(9), 61. https://www.semanticscholar.org/paper/AdvantagesandDisadvantagesofPowerPointintoXinge ngJianxiang/e982b7a3fbf0cb0304ee5049a07be21dddc863bd 